\title{
BMJ Open Quality Reducing the waiting time to initiation of infertility treatment at a tertiary care centre in India
}

\author{
K Aparna Sharma (D) , Anshu Yadav, Chithira Sridhar, Neena Malhotra, Siby Biji, \\ Kusum Kumari
}

To cite: Sharma KA, Yadav A, Sridhar $\mathrm{C}$, et al. Reducing the waiting time to initiation of infertility treatment at a tertiary care centre in India. BMJ Open Quality 2020;9:e000975. doi:10.1136/ bmjoq-2020-000975

Received 23 March 2020 Revised 29 August 2020 Accepted 20 September 2020

Check for updates

(C) Author(s) (or their employer(s)) 2020. Re-use permitted under CC BY-NC. No commercial re-use. See rights and permissions. Published by BMJ.

Obstetrics and Gynaecology, All India Institute of Medical Sciences, New Delhi, India

Correspondence to

Dr Anshu Yadav;

anshugunwal@gmail.com

\section{ABSTRACT}

Background In a low-resource and high-volume setting, it is often felt that patient care cannot be improved within the limitations of existing infrastructure and resources. However, the use of a systematic problem-solving method can bring about significant improvement even in these settings.

Aim To decrease the mean waiting time from first visit to initiation of infertility treatment by $70 \%$ within 4 weeks (130 June 2019) for patients coming to the gynaecological outpatient department (OPD).

Methods We constructed a multidisciplinary quality improvement team consisting of an academic consultant, a senior resident physician, a junior resident physician and a nurse to address the problem of long waiting times to initiation of fertility treatment. We collected baseline data from 10 consecutive women presenting to gynaecological OPD with complaints of infertility by calculating the time between their first visit to the facility and the day of performance of hysterosalpingography (HSG). The average waiting time was found to be 6 months and 25 days (mean=6.85 months; $3.5-10$ months). The team used process flow diagrams and fishbone analysis to identify various causes of these long waiting times. The main reason for the delay in starting infertility treatment was that the date for HSG was given only after seeing the endometrial aspiration report (ie, after ruling out endometrial tuberculosis as there is a risk of dissemination of tuberculosis during HSG). Also, HSG was done only once a week during a short 2-hour slot in the fluoroscopy room.

Results After the implementation of change ideas, there was significant reduction in the waiting period to starting treatment in patients with infertility. After the first change idea, the average waiting period seen in 10 consecutive patients with infertility reduced to 3.25 months, that is, by $51.8 \%$ from baseline within a 2-week interval, and there is shift in the run chart diagram. After the second change idea, the waiting time reduced to 2 months, that is, by $70 \%$, seen in the next 10 consecutive patients with infertility within the next 2 weeks' time. The results were sustained to the average waiting time of 2 months for 6 months without any additional resources.

Conclusion With a well-organised and conducted quality improvement project and team efforts, the required changes can be brought about in an established conventional healthcare delivery system and improvements can be sustained over a long period of time.

\section{INTRODUCTION}

Infertility is becoming a global health problem, has become more prevalent and is estimated to affect between $8 \%$ and $12 \%$ of reproductive-aged couples worldwide. ${ }^{1}$ In some regions of the world, the rates of infertility are much higher, reaching $\sim 30 \%$ in Sub-Saharan Africa. ${ }^{2}$ The regions with a high prevalence of infertility include South Asia, Sub-Saharan Africa, the Middle East and North Africa, Central and Eastern Europe, and Central Asia. ${ }^{3}$

Timely treatment is vital to the management of any condition, but especially so for infertility management. Delay not only adds to the patient's anxiety, but the prognosis also worsens as precious time is lost, as fertility declines with increasing maternal age, as early as 32 years old and especially after the mid-30s. ${ }^{4}$ The best surrogate marker of oocyte quality is age. ${ }^{5}$

Infertility in developing countries is a devastating burden to the social, economic and personal well-being of those affected and the burden is disproportionately borne by women. ${ }^{6}$ Psychological stress, economic hardship, social stigma, isolation, and mental and physical violence have all been described as consequences of infertility. ${ }^{7-10}$

In India, 8-10 million couples are estimated to be childless. According to the Delhi IVF and Fertility Research Centre, infertility affects one in six couples in India, ${ }^{11}$ and the recent National Family Health Survey data estimated that $3.8 \%$ of currently married women between 40 and 44 years are childless. $^{12}$

Challenges faced during infertility care in general and in low-income and middle-income countries specifically

Infertility treatment in low-income and middle-income countries is always challenging due to the high population, limited resources and low infertility care. Lack of policy decision, administrative loopholes and 
lack of efficient fund allocation lead to poor infertility care. Lack of awareness and lack of community participation lead to supply-demand gap, which further leads to faulty healthcare delivery system.

The All India Institute of Medical Sciences, New Delhi is a tertiary care government hospital in India. It is a referral centre where care is provided at subsidised rates under the All India Institute of Medical Sciences, 1956 by the government of India. About 400 patients are seen every day in the gynaecological outpatient department (OPD), with about $40 \%$ of these patients coming for infertility management. For patients with infertility visiting the OPD, there is a general protocol for workup, where the couple is evaluated by a standard set of investigations. Hysterosalpingography (HSG) is part of the investigations for tubal factor evaluation. However, certain proportion of patients may not require this or might have already undergone the procedure from some other facility. Even after removing this segment, there is a considerable volume of cases that need to be done at the centre.

The limited infrastructure and resources and the low staffing level affect the quality of care that the staff are able to deliver, especially given the high patient volume. We realised that patients had to wait for months to get investigations done and for follow-up appointments. Time is of extra essence in managing infertility, so the long waiting period to initiation of infertility treatment adds to the stress faced by the patients.

Increased waiting times are not always the result of infrastructural or resource problems. Redistribution of resources or restructuring of processes can sometimes improve outcomes.

Staff from the department had been trained in using quality improvement (QI) methods by point-of-care quality intervention and had previously done several QI projects to improve obstetric and gynaecological care for birth companion, hand washing before caesarean section and others. It was felt that QI could also be applied to solve the problem of long waiting time to initiation of fertility treatment.

\section{METHODS}

A multidisciplinary QI team was formed to address the problem of long waiting time to initiation of fertility treatment. This team consisted of an academic consultant, a senior resident physician, a junior resident physician and a nurse. We collected baseline data from 10 consecutive women presenting to the gynaecological OPD with complaints of infertility by calculating the time between their first visit to the facility and the day of performance of HSG. The average waiting time was found to be 6 months and 25 days (mean=6.85 months; $3.5-10$ months).

The aim of the QI project was to decrease the mean waiting time from the first visit to initiation of infertility treatment by $70 \%$ within 4 weeks (1-30 June 2019) for patients coming to the gynaecological OPD.
The team used process flow diagrams and fishbone analysis to identify various causes of these long waiting times.

\section{UNDERSTANDING THE PROCESS OF CARE}

Couples have to undergo a chain of investigations before infertility treatment can start. Getting all the tests done takes time as most of these are menstrual cycle-dependent and these are where delays can occur.

- First visit: history is taken and baseline investigations are advised. Hormonal profile is done during days $2-5$ of the menstrual cycle, including serum follicle stimulating hormone, luteinising hormone, prolactin and thyroid stimulating hormone.

- Second visit: the patient comes during days 2-5 of her menses and gets hormonal profile done, which was advised on the first visit. She is also given a date for endometrial aspiration (EA), which is usually after 1 month. The EA is done in the luteal phase.

- Third visit: the EA is done and the patient usually gets the report after 15 days.

- Fourth visit: the patient will collect the EA report and show it to the doctor, and if the report rules out tuberculosis a provisional date for HSG is given (around 3 months of waiting).

- Fifth visit: the final date for HSG is given.

- Sixth visit: HSG is done.

- Seventh visit: HSG report is collected (15 days after the procedure).

- Eighth visit: HSG report is shown to the doctor and a treatment plan is discussed.

Thus, it takes a minimum of 8 visits and 6-8 months to perform the investigations required and to start the infertility treatment (figure 1).

To find out the causes of prolonged waiting periods, the team used the fishbone analysis. This helped identify the various people, policy, place and procedure-related issues that contribute to the problem (table 1).

It was determined that the main reason for the delay in starting infertility treatment was that the date for HSG was given only after seeing the EA report (ie, after ruling out endometrial tuberculosis as there is a risk of dissemination of tuberculosis during HSG). Also, HSG was done only once a week during a short 2-hour slot in the fluoroscopy room.

\section{STRATEGY}

Based on an understanding of the processes and the causes identified in the analysis, the team came up with various change ideas. The change ideas were tested using successive Plan-Do-Study-Act (PDSA) cycles.

As the first change idea, we planned to provide the date for the HSG test on the same day that the EA was done, as compared with earlier when the date was provided after the EA test report. This was done by the nurse posted in the procedure room. Initially, there was some resistance from the nursing officers as they thought that this will increase 

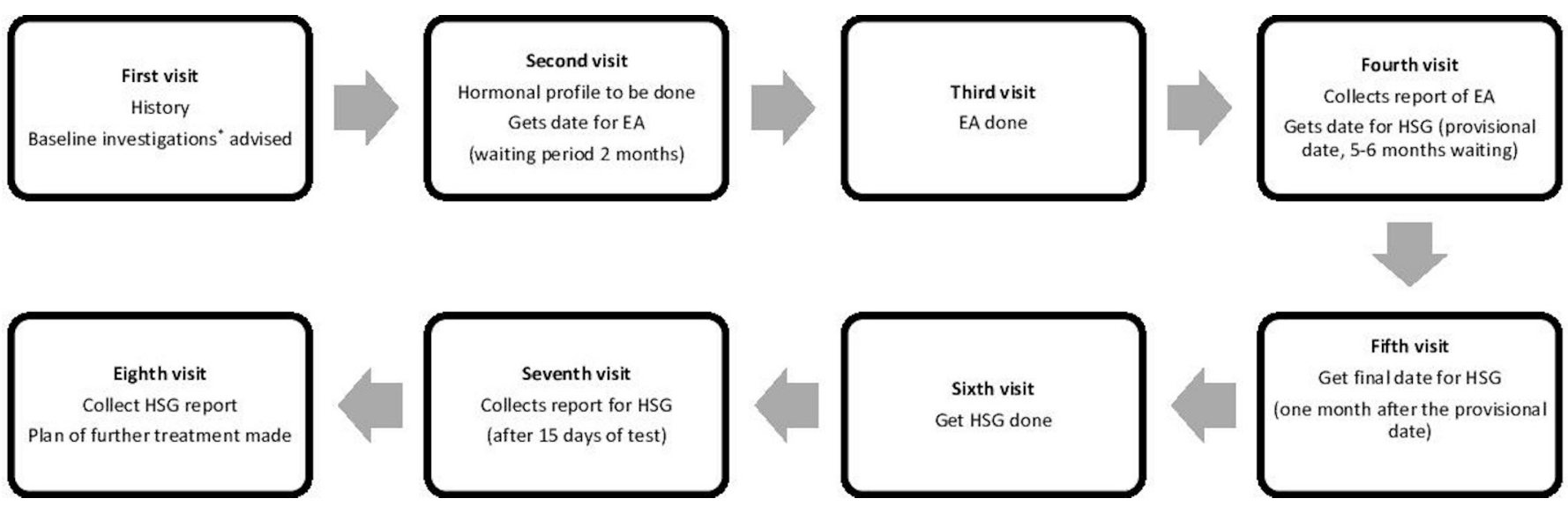

Figure 1 Steps that a patient has to undergo prior to initiation of fertility treatment and the approximate waiting period for each step. *Serum follicle stimulating hormone, luteinising hormone, prolactin, thyroid stimulating hormone, antimullerian hormone, husband semen analysis (HSA), endometrial aspiration (EA) for histopathological examination, acid fast bacilli and PCR to rule out endometrial tuberculosis, followed by hysterosalpingography (HSG) to assess tubal patency. HSA, Husband semen analysis.

their workload. After some convincing, we asked them to try this only for 1 week. At the end of the week they found that it actually decreased the crowd in the OPD. Hence, they agreed to club the two activities. Additionally, as a safeguard, we instructed the residents performing HSG to check the EA report before performing the procedure so that tuberculosis is not missed. We have found that this change reduced the number of hospital visits a patient had to make, in addition to reduction in waiting time, so we implemented this change idea. The first PDSA cycle lasted for 2 weeks (1-15 June 2019).

In the second change idea, we planned to arrange additional slots for HSG in the fluoroscopy room. Conventionally, HSG was done only for 2 hours once a week due to a presumed busy fluoroscopy room. Several other procedures from various departments were also done in the fluoroscopy room, such as barium meal, barium swallow, micturating cystogram and so on. The list of procedures in the fluoroscopy room for 1 week was analysed retrospectively. The list was discussed with the staff of the fluoroscopy room in conjunction with the administrative heads of the departments. The radiology unit reviewed their data on the procedures being done and was able to identify which services needed more time allocation. They agreed that more slots can be given to HSG as there was a considerably longer waiting list for HSG. One whole day (6 hours) was allotted exclusively for HSG, and slots for other less common procedures were rescheduled to other days of the week. We found that this change reduced the waiting period significantly during the next 2 weeks (16-30 June 2019). We implemented this change idea.

\section{MEASUREMENT}

\section{Outcome measure}

The outcome measure was the average waiting period to the start of infertility treatment.

\section{RESULTS}

After the implementation of change ideas, there was significant reduction in the waiting period to starting treatment in patients with infertility. After the first change idea, the average waiting period seen in 10 consecutive patients with infertility reduced to 3.25 months, that is, by $51.8 \%$ from baseline within a 2-week interval, and it is also seen as a shift in baseline in the run chart diagram (figure 2).

The waiting time in the next 10 consecutive patients with infertility reduced to 2 months after the second change idea. It was a $70 \%$ reduction from 3.25 months over 2 weeks' time.

The results were sustained to the average waiting period of 2 months after the first visit for 6 months without any additional resources (figure 3). We continued to collect data after the QI project had achieved its aim. The

Table 1 Causes of delay in initiation of fertility management identified using the fishbone analysis

\begin{tabular}{llll}
\hline People & Place & Process & Policy \\
\hline $\begin{array}{l}\text { Every time, a different resident } \\
\text { sees the patient. }\end{array}$ & $\begin{array}{l}\text { HSG done only once a week, every } \\
\text { Wednesday, for 2 hours, covering } \\
\text { only 10-12 cases. }\end{array}$ & $\begin{array}{l}\text { Date of HSG given only } \\
\text { after seeing the EA } \\
\text { report. }\end{array}$ & $\begin{array}{l}\text { Date of test given according } \\
\text { to the menstrual phase. }\end{array}$ \\
$\begin{array}{l}\text { The junior resident physician } \\
\text { seeing the patient misses the }\end{array}$ & & $\begin{array}{l}\text { Date of HSG given only on } \\
\text { tests to be advised. }\end{array}$ & Tuesday and Friday.
\end{tabular}

EA, endometrial aspiration; HSG, hysterosalpingography. 


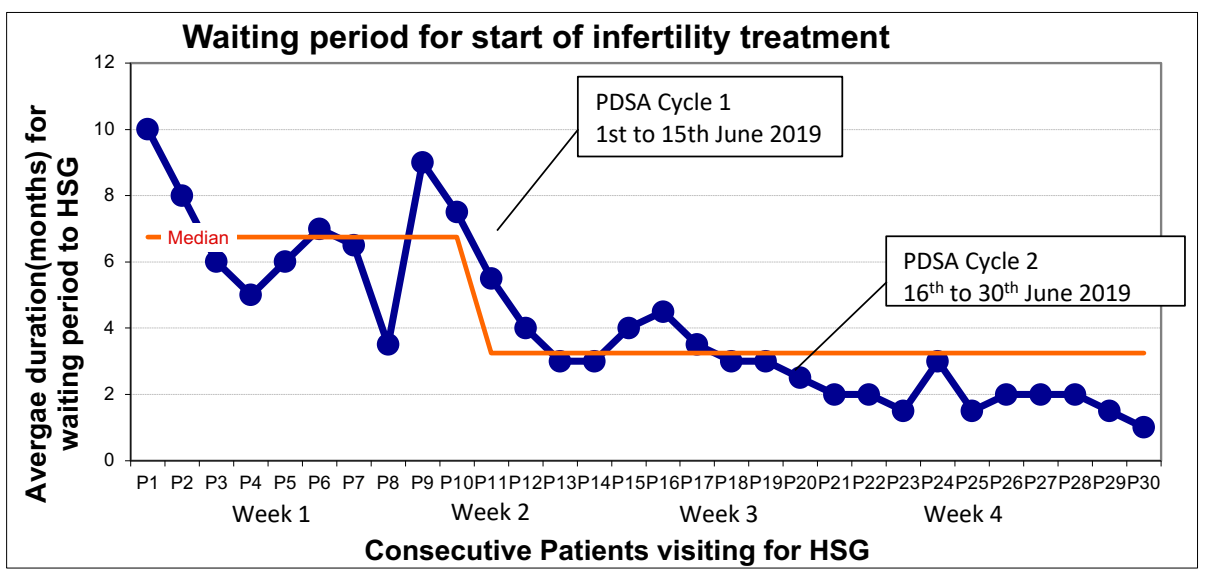

Figure 2 Run chart diagram showing the waiting time to HSG test in consecutive patients with infertility visiting the gynaecological outpatient department. HSG, hysterosalpingography; PDSA, Plan-Do-Study-Act.

changes we made were system changes and likely to result in sustained improvements. We continued to see these data at regular intervals.

\section{CHALLENGES}

Implementation of any change idea is not without its own challenges, and various problems were faced during the

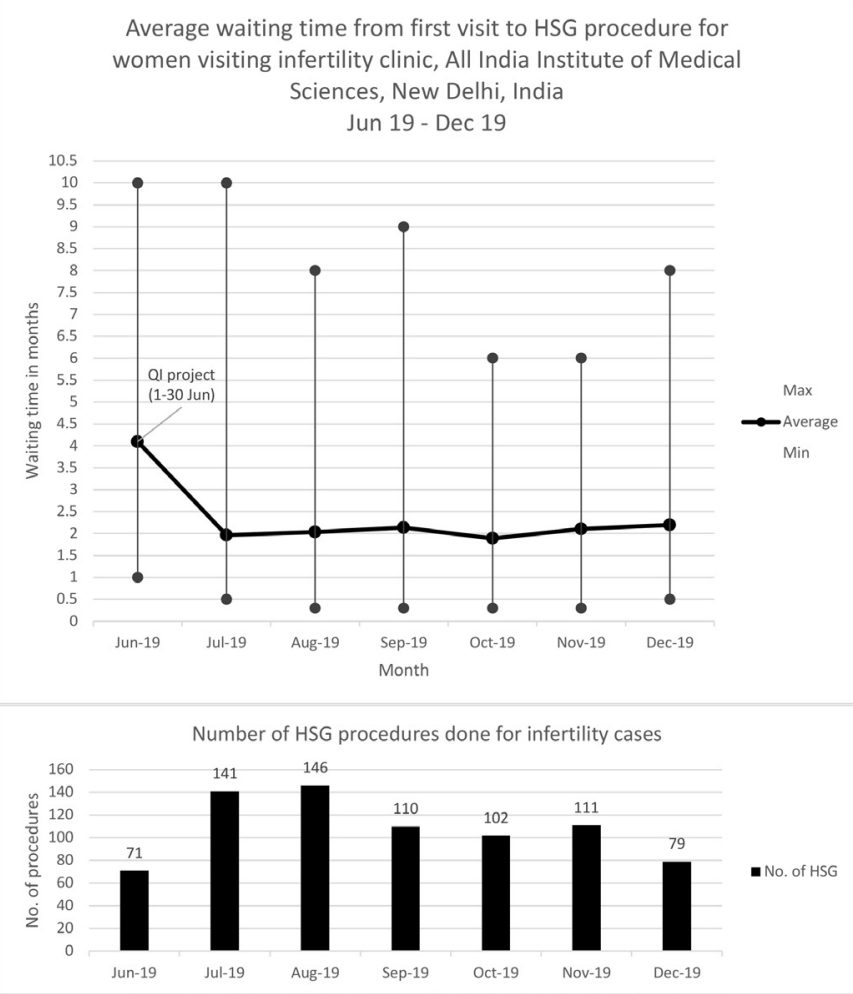

Figure 3 Follow-up data of average waiting time from first visit to HSG procedure for women visiting the infertility clinic. HSG, hysterosalpingography; QI, quality improvement. period of the study. It took significant convincing for the nurses to combine the dates for HSG and EA as it was perceived that it would increase their workload significantly. However, after initial few slots, it actually decreased crowding as two visits were being combined together.

Increasing the time for HSG from 2 hours to 6 hours in a day meant increasing the cases from 10-15 to almost 40 per day. The logistic requirement for this presented a challenge in terms of the number of instrument sets required for doing the procedure and the staff who would be doing the procedure for a whole day. For the former, some more instruments were indented with the cooperation of the nursing officer which was easily available in the hospital store. A rotation of staff posted in HSG was agreed upon between the gynaecology and radiology departments for the smooth conduct of the procedure. Also, the duty roster of the residents performing the HSG was shuffled so as to accommodate a full day of performing the procedure. Despite these challenges, with persistence and good interdepartmental coordination, the proposed changes could be achieved with desirable and sustained results within the constraints of a resource-limited setting.

\section{DISCUSSION}

In a resource-strapped setting, it is often felt that patient care cannot be improved within the limitations of existing infrastructure and resources. However, a closer look at the problem with a methodological problem analysis and targeted solutions can bring about significant improvement even in these settings. It was observed in our project that collecting data on delays can lead to improved management by allocating more resources where required.

Some procedural delays happen due to the conventional approach to diagnostic evaluation which may 
result in untoward patient experience. In our experience simple actions such as rescheduling dating protocols but reviewing reports of EA before performing HSG improved waiting times without compromising the diagnostic algorithm.

The radiology fluoroscopy unit was also able to allocate their time more efficiently. Earlier they were allocating the same number of slots to each fluoroscopic procedure irrespective of frequency. Now they allocate slots based on the frequency of procedures. Our project can help provide general direction on how to approach delays in infertility treatment in similar settings, such as in largevolume centres.

Hence, the solutions essentially depend on the context and local barriers.

\section{LIMITATIONS OF THE STUDY}

We tried to fix a problem of prolonged waiting time using the principles of QI. However, there are other processes happening simultaneously within the two departments which might not be within the control of the QI team. There were days of technical failures or when residents did not come and the procedures had to be cancelled. Also, despite the scheduled dates for the procedure, some patients did not come, while some patients were ineligible for the procedure due to menstrual cycle irregularity. All these factors can explain the variability in the waiting time data of certain patients.

This being a very specific concern, reproducibility may be limited to reproductive medicine facilities with high case load. Also, we fixed internal processes within the unit, but areas such as a dedicated staff for HSG in radiology are other potential issues that need to be addressed. They might help in further streamlining the procedure.

\section{SUMMARY}

With a well-organised and conducted QI project and team efforts, the required changes can be brought about in an established conventional healthcare delivery system and improvements can be sustained over a long period of time.

Acknowledgements The authors wish to thank nursing officer Kamal and HSG technician Renu, who helped in data collection and instrument indentation, and $\mathrm{Dr}$ Sonali Vaid for her immense support in writing and literature search.
Contributors KAS and AY contributed to the design and implementation of the research and writing of the manuscript. CS and NM contributed to data interpretation and analysis of the results. SB and KK managed the dates and dataand streamlined the logistic issues.

Funding The authors have not declared a specific grant for this research from any funding agency in the public, commercial or not-for-profit sectors.

Competing interests None declared.

Patient and public involvement Patients and/or the public were not involved in the design, or conduct, or reporting, or dissemination plans of this research.

Patient consent for publication Not required.

Ethics approval This study was exempt from ethics review according to institutional guidelines as it is a quality improvement activity.

Provenance and peer review Not commissioned; externally peer reviewed.

Open access This is an open access article distributed in accordance with the Creative Commons Attribution Non Commercial (CC BY-NC 4.0) license, which permits others to distribute, remix, adapt, build upon this work non-commercially, and license their derivative works on different terms, provided the original work is properly cited, appropriate credit is given, any changes made indicated, and the use is non-commercial. See: http://creativecommons.org/licenses/by-nc/4.0/.

ORCID iD

K Aparna Sharma http://orcid.org/0000-0002-7369-2007

\section{REFERENCES}

1 Ombelet W, Cooke I, Dyer S, et al. Infertility and the provision of infertility medical services in developing countries. Hum Reprod Update 2008a;14:605-21.

2 Nachtigall RD. International disparities in access to infertility services. Fertil Steril 2006;85:871-5.

3 Mascarenhas MN, Flaxman SR, Boerma T, et al. National, regional, and global trends in infertility prevalence since 1990: a systematic analysis of 277 health surveys. PLoS Med 2012b;9:1-12.

4 Johnson J-A, Tough S, SOGC GENETICS COMMITTEE. Delayed child-bearing. J Obstet Gynaecol Can 2012;34:80-93.

5 Committee on Gynecologic Practice. Committee opinion no. 618: ovarian reserve testing. Obstet Gynecol 2015;125:268-73.

6 Cheap IVF needed. Nature 2006;442:958.

7 Vayena E, Rowe P, David Griffin P, WHO. Introduc- tion Current Practices and Controversies in Assisted Reproduction "Medical, Ethical and Social Aspects of Assisted Reproduction". Geneva: WHO, 2002: 15-17.

8 van BalenF, Gerrits T. Quality of infertility care in poor-resource areas and the introduction of new reproductive technologies. Hum Reprod 2001;16:215-9.

9 Dyer SJ, Abrahams N, Mokoena NE, et al. Psychological distress among women suffering from couple infertility in South Africa: a quantitative assessment. Hum Reprod 2005;20:1938-43.

10 Daar AS, Merali Z. Infertility and social suffering: the case of ART in developing countries. In: Vayena E, Rowe P, David Griffin P, eds. Current Practices and Controversies in Assisted Reproduction "Medical, Ethical and Social Aspects of Assisted Reproduction". Geneva: WHO, 2004: 15-21.

11 Dutta S, Guha R. A clinico-anatomical study on the etiological factors pertaining to primary infertility in females using some common investigative procedures. J Anat Soc India 2007;56:14-17.

12 International Institute of population Sciences. National family health Survey1998-99, India. International Institute of population sciences. Mumbai, India, 2000. 